\title{
Fluorescent-Dye Doped Thin-Film Sensors for the Detection of Alcohol Vapors
}

\author{
Jonathan K. Fong1, Royce N. Dansby-Sparks', Adam C. Lamb', Thomas W. Owen², \\ Mohammad Mushfiq2, Uma Sampathkumaran'2, Kisholoy Goswami2, Scott L. Jensen', \\ Zi-Ling Xue ${ }^{*}$ \\ ${ }^{1}$ Department of Chemistry, University of Tennessee, Knoxville, USA \\ ${ }^{2}$ InnoSense LLC, Torrance, USA \\ ${ }^{3}$ NASA John C. Stennis Space Center, Stennis Space Center, USA \\ Email: xue@ion.chem.utk.edu
}

Received 17 April 2014; revised 31 May 2014; accepted 14 June 2014

Copyright (C) 2014 by authors and Scientific Research Publishing Inc.

This work is licensed under the Creative Commons Attribution International License (CC BY).

http://creativecommons.org/licenses/by/4.0/

(c) $\underset{\mathrm{EY}}{(\mathbf{B})}$ Open Access

\section{Abstract}

Fluorescence sensors based on a trifluoroacetophone compound doped in ethyl cellulose (EC) thin films have been developed for the detection of methanol, ethanol, and 2-propanol (isopropanol, PriOH) vapors. Thin-film sensors are prepared with 4-dibutylamino-4'-(trifluoroacetyl)stilbene (Chromoionophore IX or CIX) as the fluorescent dye and its solution in EC was spin-coated onto glass slides. The luminescence intensity of the dye $(555 \mathrm{~nm})$ is quenched when exposed to alcohol vapor. Tested in the range of ca. $0-1.5 \times 10^{4} \mathrm{ppm}(\mathrm{wt})$ for $\mathrm{MeOH}$ and $\mathrm{EtOH}$, and ca. $0-2.3 \times 10^{4}$ ppm for PriOH, the sensors gave detection limits of 9, 13, 21 ppm and quantification limits of 32, 43, and $70 \mathrm{ppm}$, respectively. To enhance the sensitivity of the sensors, $\mathrm{TiO}_{2}$ particles have been added to the films to induce Mie scattering, which increases the incident light interaction with the sensing films. The sensors in this work have been designed to work in a multianalyte platform for the simultaneous detection of multiple gas analytes.

\section{Keywords}

Optical Thin Film Sensors, Chromoionophore IX Dye, Alcohol Vapor Detection

\section{Introduction}

Alcohol vapor detection is an area of intense interest. Since fossil fuels are not a renewable source of energy, the need for promising alternatives such as alcohol has steadily increased in demand. Fuels heavily blended with

\footnotetext{
${ }^{*}$ Corresponding author.
}

How to cite this paper: Fong, J.K., Dansby-Sparks, R.N., Lamb, A.C., Owen, T.W., Mushfiq, M., Sampathkumaran, U., Goswami, K., Jensen, S.L. and Xue, Z.-L. (2014) Fluorescent-Dye Doped Thin-Film Sensors for the Detection of Alcohol Vapors. American Journal of Analytical Chemistry, 5, 566-580. http://dx.doi.org/10.4236/ajac.2014.59064 
alcohol have shown promise in the automotive industry [1]. In addition, methanol has been actively studied in fuel cells [2]. The increasing use of methanol as a fuel may lead to the greater exposure of methanol vapors to the general public due to, e.g., unburned fuel in the form of exhaust or from evaporation during refueling [1]. Listed as one of air toxics by the US Environmental Protection Agency, methanol vapor can cause nausea, headaches, and even blindness [3]-[5]. In 2002, an experimental physicist developed Parkinson's disease from the delayed toxic effect of long term exposure to methanol vapors without showing any signs of acute toxicity [6]. The permissible exposure limit to methanol is set at $200 \mathrm{mg} \cdot \mathrm{kg}^{-1}$ by the US Occupational Safety and Health Administration (OSHA) [5].

Detection of ethanol vapor is also an area of particular interest because of the need for responsive and reversible sensors to detect alcohol in human breath. Ethanol has been increasingly used as a blend in gasoline as well [7] [8]. While it is renewable, bio-ethanol is known to be corrosive to stainless steel and other metals/alloys [8], and gas tank corrosion has led to leaks that require detection. Since ethanol and gasoline have different physical and thermodynamic properties, engines in vehicles, especially flex fuel vehicles, need to be optimized for performance accordingly [9]. Ethanol has a lower vapor pressure than gasoline which could lead to potential cold start engine problems particularly in flex fuel vehicles [9]. These examples help to establish a critical need for ethanol detection.

A variety of commercial products used to detect ethanol vapors, specifically those used in breathalyzers for blood alcohol content (BAC), are based mainly on three different techniques: infrared (IR) spectroscopy, semiconductor metal oxides, and electrochemical fuel cells [10]-[12]. IR spectroscopy is based on characteristic vibrations of ethanol [13]. As discussed below, many compounds, however, interfere with its detection by IR. Semiconductor sensor technology often utilizes an oxide such as tin dioxide $\left(\mathrm{SnO}_{2}\right)$. When exposed to ethanol in breath samples, ethanol is adsorbed on $\mathrm{SnO}_{2}$, changing its electrical resistance. The change is measured to give the ethanol concentration [13]. Vapors of other chemicals may be adsorbed on $\mathrm{SnO}_{2}$, leading to interferences. Fuel cell breathalyzers catalyze the oxidation of ethanol and measure the electrical voltage to determine the concentration of alcohol present [13]. Fuel cell breathalyzers are less susceptible to interferences. A recently patented breathanalyzer uses silica gel impregnated with a sulphochromic [Cr(VI) $+\mathrm{H}_{2} \mathrm{SO}_{4}$ ] solution [14] that may contain toxic chromate [15]. There has been ongoing and continued research in the field of alcohol detection such as miniature GC [16] and bioelectronic gas sensors (biosniffers) [17] to improve and advance alcohol analyzers based on other methods.

Highly sensitive detection of 2-propanol is needed by NASA (National Aeronautics and Space Administration) for a new rocket engine which is designed to be used at altitudes of approximately 30,480 m [18] [19]. To simulate these conditions, a vacuum must be produced by steam generated through the combustion of 2propanol with liquid oxygen [18] [19]. Similarly to methanol, OSHA Permissible Exposure Limit for PríOH is $400 \mathrm{mg} \cdot \mathrm{kg}^{-1}$ TWA (Time-Weighted Average) [20] and prolonged exposure to 2-propanol vapor can cause irritation of the respiratory system and mucous membranes and, at higher concentrations, cause central nervous system depression [21]. It has also been reported that the ingestion of 2-propanol is also not uncommon among alcoholics as a substitute for conventional alcoholic drinks [22]. Fatalities have been reported due to the ingestion of 2-propanol and there have been some cases of routine DUI road-traffic investigations involving individuals admitting to drinking commercial products comprised of almost pure 2-propanol before the traffic incident [22]. Therefore, a need for a near real-time sensor for the remote detection of $\mathrm{Pr}^{\mathrm{i}} \mathrm{OH}$ would be beneficial for 2-propanol vapor and rocket plume testing conditions.

In addition to commercial breathanalyzers, other techniques developed to sense alcohol vapor are largely based on the solvatochromatic effect (or their physical changes inside the sensor matrices). Stevens and Akins have developed a fluorescence sensor using the dye Coumarin 481 specifically for methanol vapor at $150 \mathrm{mg} \cdot \mathrm{kg}^{-1}$ [23]. The sensor in that study displays fluorescence quenching upon exposure to methanol as a result of physical changes inside the sensor matrix. However, the fluorescence intensity is not fully recoverable possibly because of an irreversible morphological change in the film [23]. Bangalore and coworkers have shown that detection of methanol vapor from $400-7000 \mathrm{mg} \cdot \mathrm{kg}^{-1}$ in air can be accomplished by open path FT-IR spectroscopy, but this method requires quite bulky and expensive instruments that are not field deployable [11]. Pang and coworkers have used the sol-gel method to fabricate a planar waveguide ring resonator sensitive to ethanol with spectral dips that are red shifted when exposed to ethanol [24]. However, this technique has a small dynamic range (0 $160 \mathrm{mg} \cdot \mathrm{kg}^{-1}$ ) and the sensitivity of the resonant wavelength may be detected more precisely by spectroscopy than from loss measurements [24]. Hunter and coworkers have developed a technique for the measurement of 
ethanol concentrations in aqueous mixtures with a detection limit of $40 \mathrm{mg} \cdot \mathrm{kg}^{-1}$, in which ethanol vapor is transported by a permeable membrane to a microelectromechanical (MEMS) chemi-capacitor array [25]. The dielectric constant of a polymeric material in the micro-capacitors increased upon absorption of ethanol vapor, leading to the measurement. All of the aforementioned techniques are based on physical (rather than chemical) detection methods.

Optical sensors are convenient to use for a variety of analytes because of their various advantages. Optical sensors are inexpensive, easy to produce, and therefore can be made into disposable chemical sensors if required [26] [27]. Maffei and coworkers have recently reported an alcohol vapor sensor using a fluorescent phosphonate cavitand. The reactions are mainly through hydrogen bonding between alcohols and the phosphonate cavitand, and the sensor is sensitive for C1-C4 alcohols ranging from 4 to $600 \mathrm{mg} \cdot \mathrm{kg}^{-1}$ [28]. Other techniques of interest for alcohol detection involve silicon quantum dots coupled to fiber optics [29] and developing optical sensors from tetraphenyl porphyrins [30]. Also, Mohr and coworkers have produced an optical sensor for alcohols using a synthesized fluorescent compound Chromoionophore IX (CIX) prepared in a poly(vinyl chloride) (PVC) membrane for the detection of alcohols in the liquid phase [31]-[33]. We have adapted and developed sensors based on the fluorescence of CIX for the detection of methanol, ethanol, and 2-propanolin the gas phase.

With the goal of detecting various alcohols in the gas phase, optical sensors were developed using an ethyl cellulose (EC) thin-film matrix to encapsulate the dye in our studies. Their preparation has been optimized to produce sensitive sensors for alcohol vapors. The EC matrix has showed ideal performance and was selected after evaluating other matrices such as PVC and silica sol-gel. $\mathrm{TiO}_{2}$ particles were used in the sensor films to induce Mie scattering, which increased the incident light interaction with the sensing films, and enhanced the sensitivity of the sensor [34]. The sensors show fast, reversible responses, and they are easily regenerated by flushing the sensor with nitrogen gas. The optical sensors have also been designed to function in a multianalyte platform for the simultaneous detection of multiple gas analytes. The studies here follow our earlier work in the development of optical sensors for chemicals in both liquid and gas phases [35]-[39].

\section{Experimental}

\subsection{Chemical Reagents and Materials}

Ethyl cellulose (49\% ethoxy content, MP Biomedicals), tridodecylmethylammonium chloride (TDMACl, 98\%, Sigma-Aldrich), methyltriethoxysilane (MTEOS, Aldrich), tetramethoxysilane (TMOS, Aldrich), $\mathrm{R}^{706} \mathrm{TiO}_{2}$ (DuPont), and dioctyl sebacate (DOS, Sigma-Aldrich) were used as received. Methanol (99.9\%), ethanol (99.9\%), 2-propanol (99.9\%), and other chemicals were purchased from Fisher Scientific. Chromoionophore IX (CIX) was either purchased from Fluka or prepared by the reported procedure [26].

Standard microscope slides (Corning) were used to cut $1 \times 1 \mathrm{~cm}^{2}$ glass sensor substrates. They were washed in a piranha solution (concentrated $\mathrm{H}_{2} \mathrm{SO}_{4}$ and $30 \% \mathrm{H}_{2} \mathrm{O}_{2}$ in 3:1 ratio) for 30 min, followed by rinses first with deionized water and then with acetone, methanol, and ethanol. These slides were then dried in an oven before use. N-type [100] silicon wafers were similarly cleaned for deposition of thin film sensors that were then used for characterization by scanning electron microscopy (SEM).

A $0.9900 \% \mathrm{CO}_{2}$ gas tank (Airgas), odorless kerosene (Acros), acetone (Fischer), hexanes (Fischer), 29\% aqueous ammonia solution, and food products, specifically bread, were used in the interference tests. To expose $\mathrm{CO}_{2}$ gas to Sensor $\mathbf{A}$, the $\mathrm{CO}_{2}$ gas tank was directly connected to one of the flowmeters. After establishing a $\mathrm{N}_{2}$ baseline, $\mathrm{CO}_{2}$ gas $(0.9900 \%)$ was introduced into the gas stream. In the interference tests involving kerosene, acetone, hexanes, and aqueous ammonia, approximately $50 \mathrm{~mL}$ of each analyte were placed into a temperature controlled jacketed gas impinger for their respective tests. After a baseline was established for Sensor A, nitrogen gas was introduced to the impinger to bubble the specific interferent vapor into the sensor flowcell, where the response was recorded. To test for food products, a breathing mask was fitted into the inlet of the flowcell and a volunteer would breath into the mask several times to establish a baseline of the breath and then ingest bread products. The volunteer would then breathe into the mask again to see if there were any differences between the two experiments.

\subsection{Preparation of EC Sensor Films (Sensors A, B and C)}

A custom-built spin-coater was used to make the thin films.Ethyl cellulose $(\sim 0.235 \mathrm{~g})$ was dissolved in a 4:1 
mixture of toluene $(8 \mathrm{~mL})$ and ethanol $(2 \mathrm{~mL})$ to give a solution $(2.5 \%$ wt EC) which, after several tests, was found to be of the optimal for the deposition of the sensor thin films. This solution was sonicated for $20 \mathrm{~min}$ and stirred to ensure that ethyl cellulose was completely dissolved. Then CIX (1 - 2 mg) and TDMACl (0.28 mg) were dissolved into $1.00 \mathrm{~g}$ of the solution with stirring. The ethyl cellulose solution containing the dye was pippetted on a cleaned glass slide $\left(\sim 1 \times 1 \mathrm{~cm}^{2}\right)$, which was on the spin coater, and drawn to the edges of the glass slide with a plastic pipette tip. The slide was then spun at $2600 \mathrm{rpm}$ (revolutions per minute) for approximately 30 s. Schlenk tubes were used to store the freshly made thin-film sensors (Sensor A) under vacuum prior to use.

Sensors were also prepared by incorporating $\mathrm{TiO}_{2}$ particles (360 nm diameter) to induce the Mie scattering. In the preparation of these sensors, $\mathrm{R} 706 \mathrm{TiO}_{2}$ particles $(\sim 3.7 \mathrm{mg})$ were added to $\mathrm{EtOH}(5 \mathrm{~mL})$ and sonicated for 20 min to disperse the particles. The EtOH solution containing the $\mathrm{TiO}_{2}$ particles $(100 \mu \mathrm{L})$ was added with additional EtOH $(1.9 \mathrm{~mL})$ and then mixed with toluene $(8 \mathrm{~mL})$ to give an ethyl cellulose solution $(2.5 \% \mathrm{wt}$ EC). Sonication was used to ensure that ethyl cellulose was completely dissolved. Thin film sensors on glass slides were prepared from this EC solution (Sensor B) in a process similar to that described above, and then stored under vacuum in a Schlenk tube before use.

Sensor $\mathbf{C}$ was prepared on silicon wafers as Sensor A.

\subsection{Instrumentation and Analytical Procedures}

A Perkin-Elmer LS55 luminescence spectrometer with a pulsed Xe source was used for fluorescence measurements. The spectrometer was set at the following parameters: $\lambda_{\mathrm{ex}}=445 \mathrm{~nm}, \lambda_{\mathrm{em}}=555 \mathrm{~nm}, 10 \mathrm{~nm} \mathrm{slits,} 810 \mathrm{~V}$ PMT detector voltage, and a $515 \mathrm{~nm}$ emission cutoff filter. For time-based signal measurements, a signal reading was taken every $0.1 \mathrm{~s}$. To improve the signal-to-noise ratio $(\mathrm{S} / \mathrm{N})$, signal averaging was used by the arithmetic mean of a point and the points before and after. Sensors were placed in a brass flow cell constructed to fit with a front surface sample cell holder purchased from Perkin-Elmer.

The vapor pressure of each alcohol at various temperatures was calculated by using the Antoine equation (Equation (1)), where $A, B$ and $C$ are constants over a defined temperature ( $T$ in $K$ ) range [40].

$$
\log p=A-\frac{B}{T+C}
$$

A custom-made, jacketed gas impinger (Figure 1) containing an alcohol liquid was used. The lid for the bubbler contained a medium frit gas diffuser immersed in the alcohol, and the lid was sealed by an O-ring and clamp. On top of the lid, there was a gas inlet for nitrogen gas and an outlet for the alcohol-saturated gas. The temperature of the jacketed impinger was controlled by a Thermo Haake temperature controller at $-15.0,-7.0$, and $0.0^{\circ} \mathrm{C}$ to give $1.000 \% \mathrm{MeOH}\left(\mathrm{wt} \%, 1.549 \times 10^{4} \mathrm{ppm}\right), 1.000 \% \mathrm{EtOH}\left(1.587 \times 10^{4} \mathrm{ppm}\right)$, and $1.000 \% \mathrm{Pr}^{\mathrm{i}} \mathrm{OH}$ $\left(2.310 \times 10^{4} \mathrm{ppm}\right)$, respectively. Two separate mass flow controllers (MKS Instruments) (Figure 1) were connected to the inlet of the flow cell in the fluorescence spectrometer, and they were used to control the ratio of nitrogen gas and the gas from the impinger to obtain an accurate alcohol concentration. The outlet of the flowmeter was linked to a sealed vial which was attached to a separate bubbler to prevent the backflow of gases.

SEM images of Sensor C were taken using a Leo 1525 Field Emission Scanning Electron Microscope.

\section{Results and Discussion}

\subsection{Dye Sensing Mechanism}

The CIX dye, a trifluoroacetyl, reacts with alcohol to give a hemiacetal (Figure 2) and in the process quenches the fluorescence of the dye. However, formation of the hemiacetal takes approximately $20 \mathrm{~h}$ to complete. Mohr and coworkers found that a quaternary ammonium hydroxide, TDMACl, catalyzes the reaction resulting in an immediate conversion of the trifluoroacetyl group to the hemiacetal upon exposure to alcohol [33]. To our knowledge, the dye, CIX, has not been used for gas phase detection of alcohols or encapsulated in an ethyl cellulose matrix.

\subsection{Matrix Effects on Sensor Response}

Initially, PVC sensors (Sensor D) were made following the formulation by Mohr and coworkers [33]. Upon exposure to air for several days, the PVC films lost a majority of their orange color, but were still responsive when 


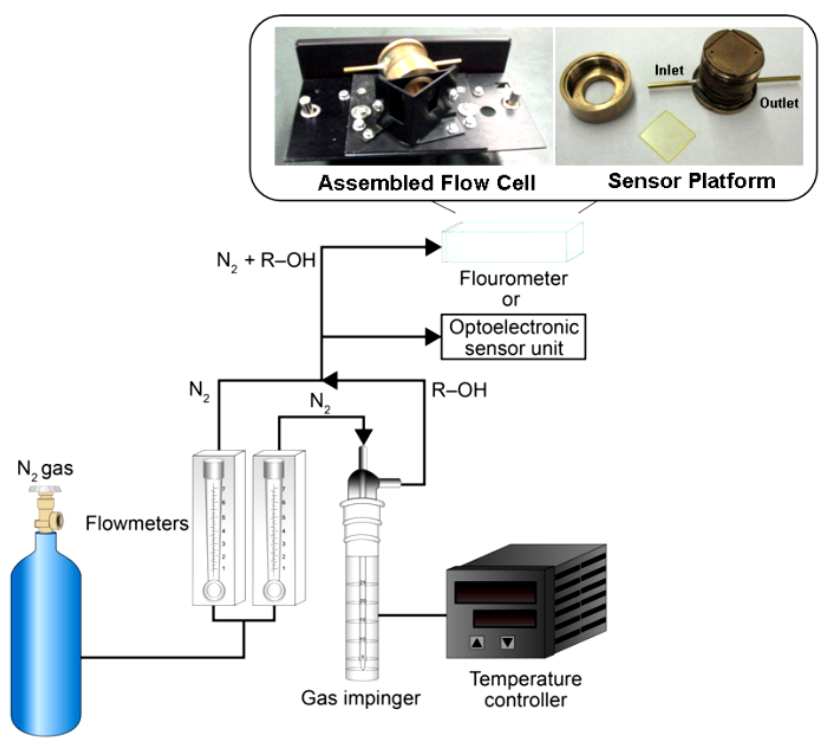

Figure 1. Schematic diagram of the instrumental set-up.

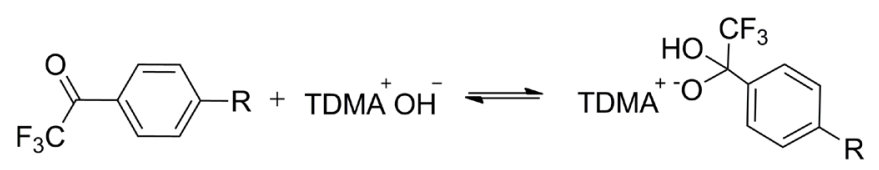

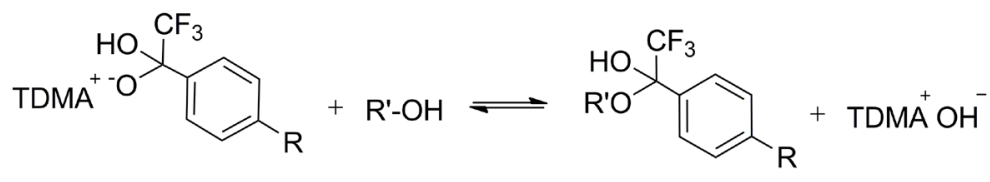

$$
\begin{aligned}
& \mathrm{R}=\mathrm{HC}_{-\mathrm{NBu}_{2}} \quad \mathrm{Bu}^{\mathrm{n}}=\mathrm{n} \text {-butyl } \\
& \mathrm{TDMA}^{+}=\text {tridodecylmethylammonium cation } \quad \mathrm{R}^{\prime}-\mathrm{OH}=\text { alcohol }
\end{aligned}
$$

Figure 2. Proposed mechanism for the reaction between the dye and an alcohol catalyzed by TDMACl [33].

tested under $1.000 \% \mathrm{Pr}^{\mathrm{i}} \mathrm{OH}$ pulses. The sensors, with an excitation peak at $450 \mathrm{~nm}$, produced an emission peak at $540 \mathrm{~nm}$ (Figure S1, Appendix). During pulses of nitrogen and 1.000\% Pri ${ }^{\mathrm{i}} \mathrm{H}$ vapor, Sensor D showed quick response times by displaying a decrease in emission intensity and fast recovery times suitable for online measurements (Figure S2, Appendix). In order to increase the sensitivity, Sensor $\mathbf{E}$ was prepared with twice the dye content. In the $0.036 \%$ - 1.000\% Pri OH vapor range (Figure S3, Appendix), Sensor $\mathbf{E}$ showed better sensitivity. However, the signal was noisy and it required signal averaging and baseline correction to adjust for the baseline drift.

Sol-gel sensors (Sensor F) were then explored as another alternative matrix for CIX. Figure S4 shows the response of the sol-gel sensor to $1.000 \% \mathrm{Pr}^{\mathrm{i}} \mathrm{OH}$ pulses, Appendix. Initially, the response to $\mathrm{Pr}^{\mathrm{i}} \mathrm{OH}$ was quick, but after switching back to nitrogen gas, the response was higher than the initial baseline, indicating that the sol-gel matrix perhaps has an affinity for alcohols and once exposed to alcohols reversibility may be problematic.

After several comparison tests, ethyl cellulose (EC) was found to be the best matrix to encapsulate the dye CIX. A focus on EC as the matrix for CIX also helped to provide consistency with other sensors previously studied by Innosense LLC in a multi-channel sensing platform. Sensor A produced an emission peak at $555 \mathrm{~nm}$ when the dye was excited at $445 \mathrm{~nm}$ (Figure 3).

Figure 4(a) shows a section of a uniform pitted surface of Sensor $C$ on a silicon substrate at $900 \times$ magnification from SEM imaging. Figure 4(b) displays a cross section of Sensor $\mathbf{C}$ at $3000 \times$ magnification that has a 


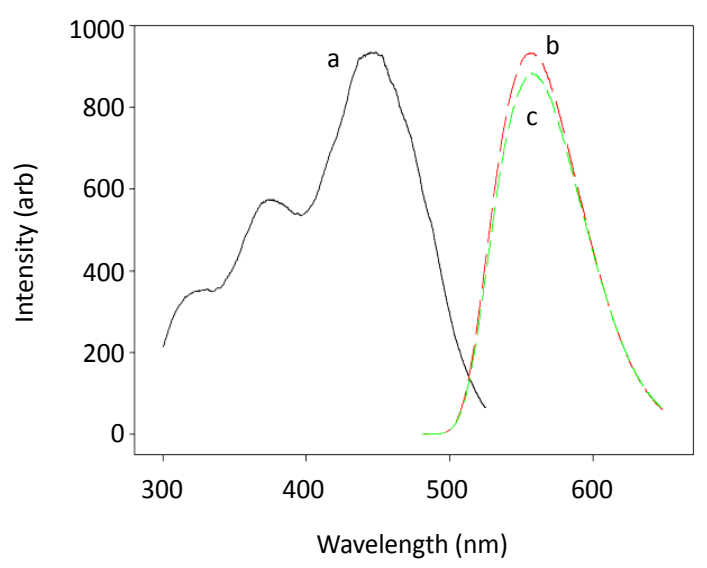

(a)

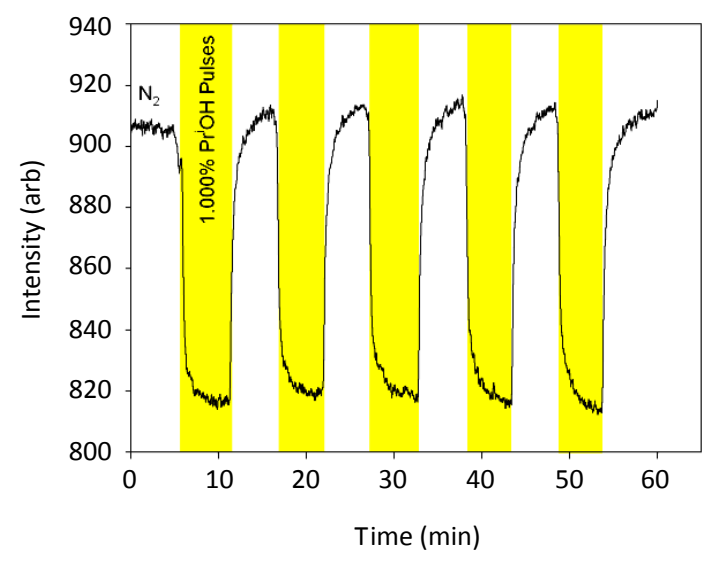

(b)

Figure 3. (a) Spectra of Sensor A: a. excitation; b. emission; c. emission after exposure to 1.000\% PríH; (b) Time-based emission at $555 \mathrm{~nm}$ demonstrating a signal quenching response when exposed to $1.000 \% \mathrm{Pr} \mathrm{iH}^{\mathrm{O}}$ in nitrogen gas without signal averaging or background correction. arb = arbitrary unit.

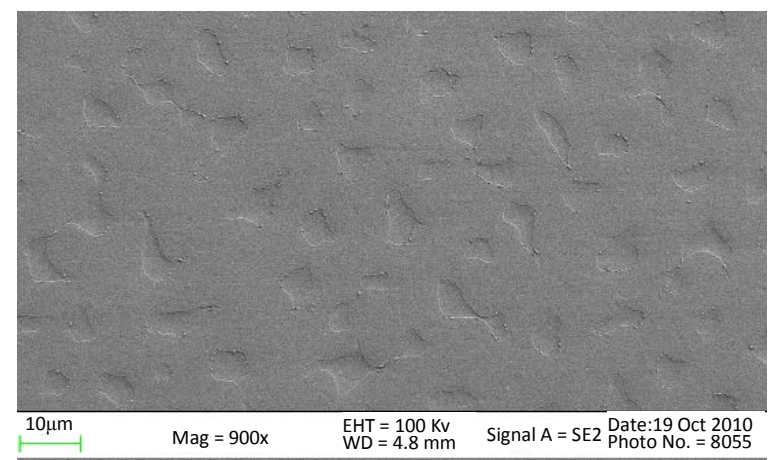

(a)

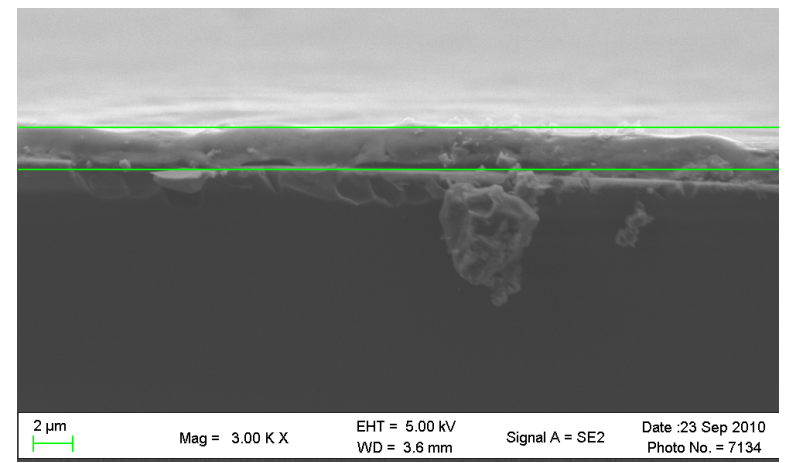

(b)

Figure 4. SEM images of Sensor C: (a) Surface; (b) Cross section.

thickness of 1 - $2 \mu \mathrm{m}$, highlighted by the two parallel lines in the image. The surface of the sensor shows features ("pitting") consistent with phase separation that occurs during the processing of the sensor.

\subsection{Mie Scattering with $\mathrm{TiO}_{2}$ Particles}

In order to increase the sensitivity of the indicator dye, $\mathrm{TiO}_{2}$ particles were incorporated into ethyl cellulose thin films. $\mathrm{TiO}_{2}$ particles scatter wavelengths in the visible range about equally [34]. The scattering of light by the $\mathrm{TiO}_{2}$ particles within the sensing matrix allows for a more effective interaction of light with the indicator molecules in the sensing layer, thus effectively increasing the path length without using thicker sensing layers [34]. The optimum particle size would be approximately 0.5 times the wavelength of interest which, in this case, would be around 250 - $350 \mathrm{~nm}$ for the emission wavelength of $550 \mathrm{~nm}$ from the dye. This method was adapted from $\mathrm{CO}_{2}$ sensors that we developed recently [39]. One possible method using $\mathrm{TiO}_{2}$ particles would be to prepare size-controlled $\mathrm{TiO}_{2}$ particles so that it would correspond to the optimum particle size needed for the emission wavelength. Nakata and coworkers have fabricated and characterized self-organized porous $\mathrm{TiO}_{2}$ particle layers where the particle size can be modified depending on the calcination temperature and time [41]. You and coworkers have also developed a process to prepare submicron-sized porous $\mathrm{TiO}_{2}$ particles by a single-step swelling process of polystyrene template particles with titanium (IV) isopropoxide (TTIP) [42]. However, commercial $\mathrm{TiO}_{2}$ particles R706 were used instead because it was inexpensive and readily available. Figure 5 shows the response of $\mathrm{TiO}_{2}$-doped Sensor $\mathbf{B}$. The addition of $\mathrm{TiO}_{2} \mathrm{R} 706$ particles resulted in an increase in the emission intensity. This is most likely because the median size of R706 particles, at $360 \mathrm{~nm}$ [43], is close to the 250 - 350 nm range indicated above. Moreover, according to the DuPont's R706 product sheet, small $\mathrm{TiO}_{2}$ particles scatter 


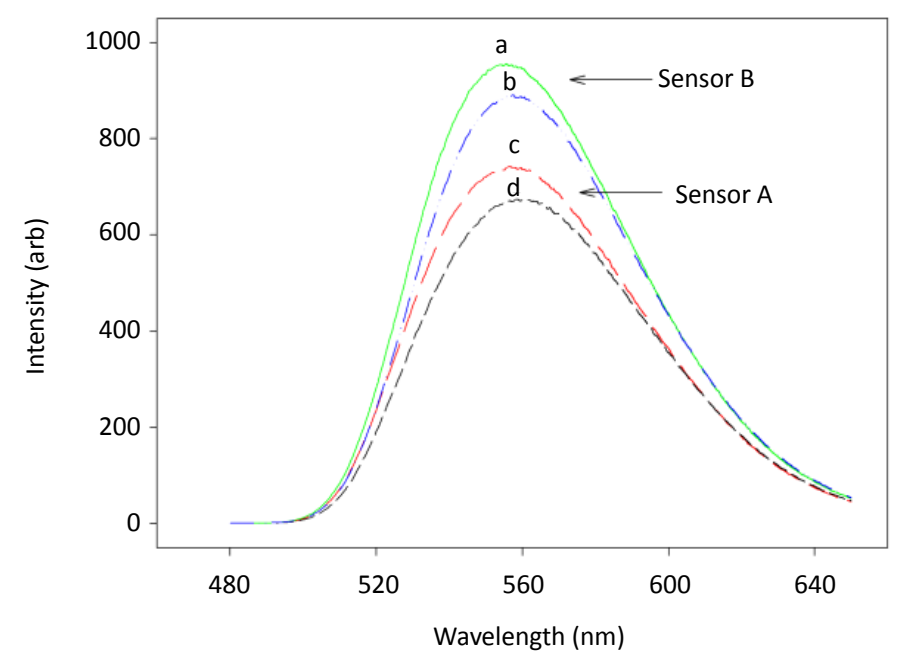

Figure 5. Comparison between Sensor $\mathbf{A}$ and $\mathrm{TiO}_{2}$-doped Sensor $\mathbf{B}$; (a) Sensor B; (b) Sensor B when exposed to $1.000 \%$ PrïH; (c) Sensor A; (d) Sensor $\mathbf{A}$ when exposed to $1.000 \% \mathrm{Pr}^{\mathrm{i} O H}$.

blue light more effectively than those with larger particle sizes [43]. In addition, R706 is ideal for the prototype optoelectronic device using a blue LED as its light source discussed below.

\subsection{Analytical Performance}

As indicated earlier, reactions of the dye CIX with alcohols forming hemiacetals are selective. Primary alcohols with increasing chain lengths show an increasing ratio of the trifluoroacetyl form rather than the product hemiacetals [33]. Figure 6 shows the sensitivity of the EC sensor towards $\mathrm{MeOH}, \mathrm{EtOH}$, and $\mathrm{Pr}^{\mathrm{i}} \mathrm{OH}$, respectively. Linear calibrations are obtained over large concentration ranges. The detection limits are $9,13,21 \mathrm{mg} \cdot \mathrm{kg}^{-1}$, and the quantification limits are 32, 43, and $70 \mathrm{mg} \cdot \mathrm{kg}^{-1}$, respectively, for $\mathrm{MeOH}, \mathrm{EtOH}$, and $\mathrm{Pr}^{\mathrm{i}} \mathrm{OH}$ vapors. The data show that the sensors are in general more sensitive to less bulky alcohols. Since CIX reacts with different alcohols, it is important to place the sensor in a specific location where the type of alcohol is known. For example, the alcohol sensor could be positioned to detect methanol leaks from fuel cells that are used in microelectronics or be adapted into breathalyzers for ethanol intoxication.

Compared to other previously mentioned studies of alcohol sensors, the EC-CIX sensors developed in this study have a much higher dynamic range and lower limit of detection for the alcohols investigated. Commercial alcohol gas sensors such as the ones used in breathalyzers usually have a sensor accuracy of \pm 0.01 blood alcohol content (BAC), according to commercial product specifications, which indicates the readings can vary by as much as $100 \mathrm{mg} \cdot \mathrm{kg}^{-1}$ [44]-[46]. While the EC-CIX sensors in this study are not totally unaffected by interferences such as moisture and amines, they are less sensitive to other interferent constituents that are found in rocket fuel and plumes such as $\mathrm{CO}_{2}$ and kerosene. The interference studies suggest that the alcohol sensors should be used in environments where the analyte gas is known so interferent vapors such as moisture/amines and other specific alcohols do not interfere in the detection. The research here shows that EC-CIX sensors may be considered an option as a sensitive alcohol sensor for detection in rocket plumes as well as being adapted and providing an improvement to general alcohol sensing device.

\subsection{Storage Conditions and Long Term Studies}

Unlike the PVC sensors (Sensors $\mathbf{D}$ and $\mathbf{E}$ ), the EC sensors (Sensor A) were able to keep their fluorescent orange color and demonstrated durability under ambient environment. An EC matrix helped to stabilize the baseline response which was observed by the small difference between the original and baseline corrected response (Figure S5) when the sensor was exposed to $\mathrm{Pr}^{\mathrm{i} O H}$ vapor, Appendix. Since the EC thin-film sensors do not lose their initial sensitivity in ambient environment, a long term study was performed to test the durability of the sensors. In order to simulate real-world field tests, Sensor As were wrapped in a lint-free cloth and then covered 


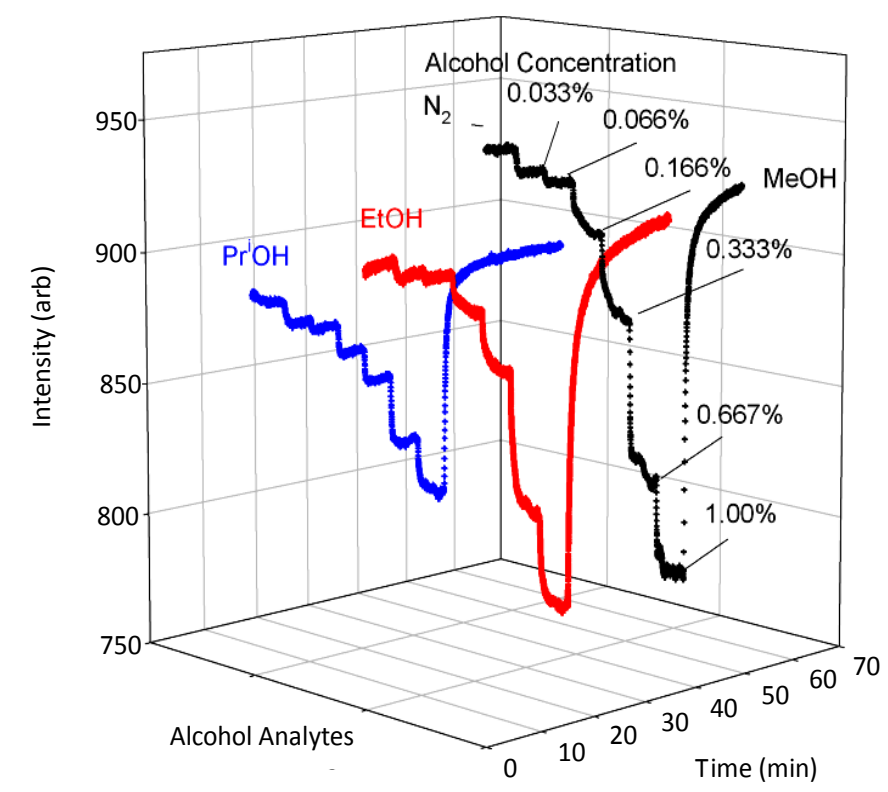

Figure 6. Response of Sensor A to MeOH vapors-Calibration: $y=$
$0.1517 x-0.0021\left(R^{2}=0.998\right)$ based on data in the range of $0 \%-1.000 \%$
$\left(0-1.549 \times 10^{4} \mathrm{ppm}\right) \mathrm{MeOH}$; EtOH vapors-Calibration: $y=0.3476 x-$
$0.0045\left(R^{2}=0.996\right)$ based on data in the range of $0 \%-1.000 \%(0-$
$\left.1.587 \times 10^{4} \mathrm{ppm}\right) \mathrm{EtOH}$; and PrOH vapors-Calibration: $y=0.0926 x+$
$0.0123\left(R^{2}=0.998\right)$ based on data in the range of $0 \%-1.000 \%(0-$
$\left.2.310 \times 10^{4} \mathrm{ppm}\right) \mathrm{Pr}{ }^{i} \mathrm{OH}$.

in aluminum foil to protect the sensors from light. Afterwards, the sensors were placed in sealable bags. Fluorescence measurements were performed every 2 weeks on the same sensor (Sensor A1), which was compared to a freshly opened sensor from the same batch. Over a period of eight months, Sensor A1 began to fluctuate in baseline (Figure S6) but the sensor still showed sensitivity when exposed to alcohol vapor ( $\left.\mathrm{Pr}^{\mathrm{i}} \mathrm{OH}\right)$. In comparison, freshly opened sensors for each measurement showed a baseline and sensitivity similar to that of Sensor A1 from month 1. This long term study demonstrates that Sensor A is able to optimally detect alcohol for 3 months before it needs to be replaced, and the sensor can remain sensitive for up to a year.

\subsection{Multi-Channel Prototype Platform}

To demonstrate that these alcohol sensors can be used in the field, InnoSense LLC has designed and built a miniaturized multi-channel optoelectronic device that can test up to seven different sensors simultaneously from a blue LED light source. Each channel has a slot for an optical filter to enable absorbance or fluorescence based measurements and longpass filters $(500 \mathrm{~nm})$ were used to examine the EC-CIX alcohol sensors. Within the optoelectronic sensor unit, there is a built-in temperature and humidity probe to monitor temperature and relative humidity during the testing period. Therefore, any contribution from humidity can be subtracted from the signal, thus giving the signal arising from the alcohol analyte itself. The optoelectronic sensor unit can be connected to a PC where data acquisition is monitored by LiveGraph software. The sensor unit was evaluated by testing three alcohol sensors (Sensor A) and an EC blank and exposing these sensors to varying concentrations of $\operatorname{Pr}^{\mathrm{i}} \mathrm{OH}$ ranging from $0 \%-1.000 \%$. Data was taken every $5 \mathrm{~s}$. Figure 7 displays the results from the sensor unit. Each alcohol sensor shows a similar response to the other and demonstrates an expected decrease in signal upon exposure to $\mathrm{Pr}^{\mathrm{i}} \mathrm{OH}$. The sensors showed minute changes in signal within the optoelectronic device when exposing the alcohol sensors to $\mathrm{CO}_{2}$ gas. However, these results were expected given the previous results above.

\subsection{Interference Study}

Another challenge for detection in optical sensors is interferences. To evaluate the response of the alcohol sensor 

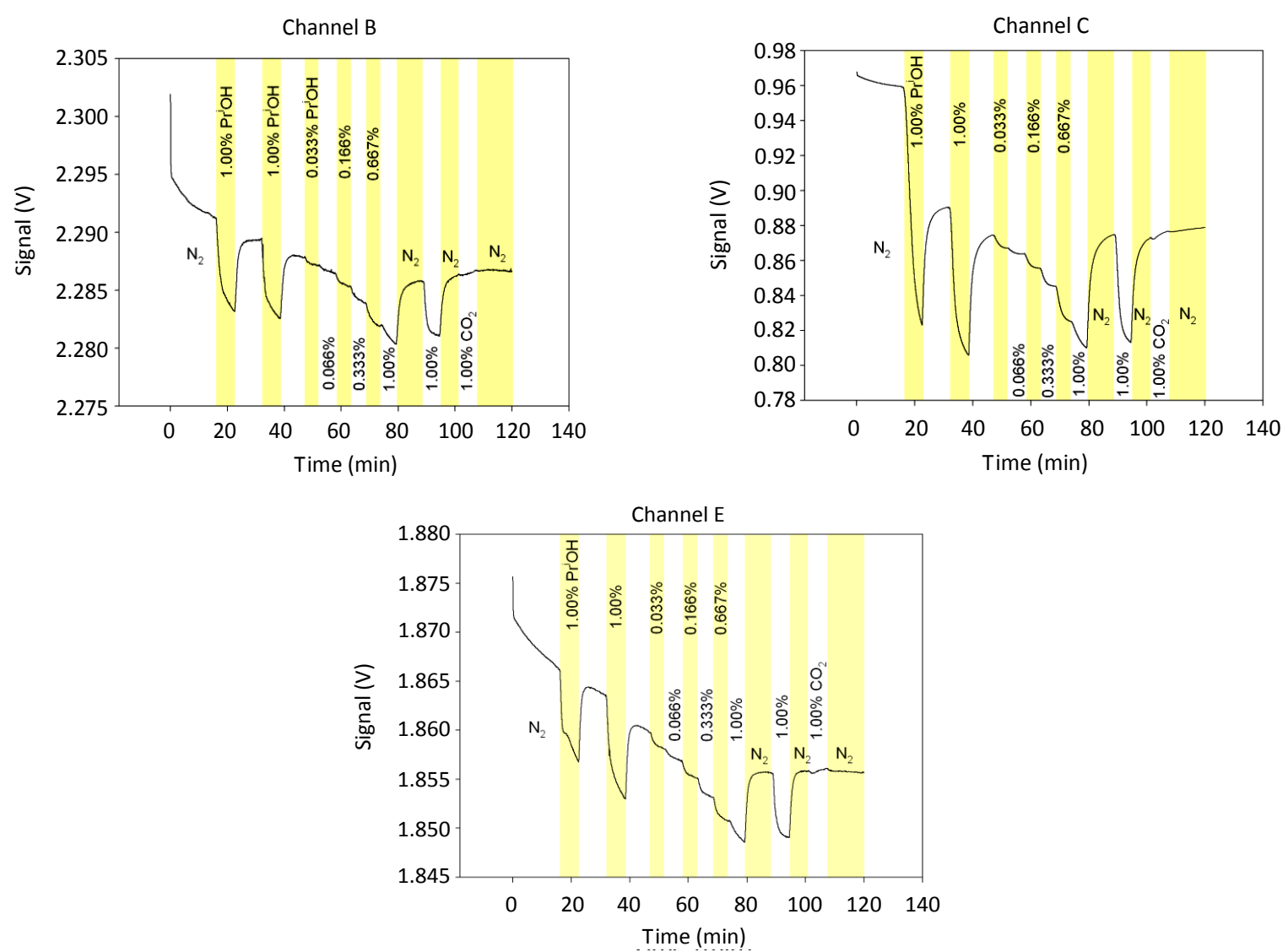

Figure 7. Response of three alcohol sensors (Sensor A) in the prototype optoelectronic device in channels B, C, and E when exposed to $\mathrm{Pr}$ i $\mathrm{OH}$ vapor and $\mathrm{CO}_{2}$.

to interferent vapors, carbon dioxide $\left(\mathrm{CO}_{2}\right)$, kerosene, ammonia $\left(\mathrm{NH}_{3}\right)$, moisture $\left(\mathrm{H}_{2} \mathrm{O}\right)$, hexanes, acetone, and food were directly exposed to Sensor $\mathbf{A}$ in triplicate and recorded. Kerosene is a rocket fuel, and $\mathrm{CO}_{2}$ is a major component of rocket plumes. $\mathrm{NH}_{3}$ is a primary product of hydrazine $\left(\mathrm{H}_{2} \mathrm{NNH}_{2}\right)$ decomposition, and hydrazine has been used as a liquid rocket propellant [47] [48]. Moisture is a byproduct generated through the combustion of 2-propanol with liquid oxygen in order to simulate a vacuum for rocket testing [16]. Acetone, hexanes, and food products, specifically bread, are some of the interferences that have attributed to false positives in general commercial alcohol sensors [49].

As expected, Figure S7 shows that $\mathrm{CO}_{2}$ gas has a minute effect on Sensor $\mathbf{A}$, and the observation is consistent with the fact that $\mathrm{CO}_{2}$ does not react with the CIX dye. Exposing Sensor A to kerosene vapors caused the fluorescence of the sensor to slightly quench in intensity, suggesting that the introduction of the hydrophobic kerosene to the sensor film may have changed the environment, shifting to a small degree the equilibrium of the reaction between the CIX dye and alcohol (Figure 2). It is expected that vapors of other organic hydrocarbons may lead to a similar, small effect.

However, exposing Sensor $\mathbf{A}$ to ammonia vapor and moisture caused a large decrease in fluorescence of the sensor. Other amines, especially primary amines, may react with the CIX dye and quench its fluorescence [50]. Moreover, moisture can react with the CIX dye, a ketone, forming geminal diols and thus affect the reaction of the dye with alcohol [50]. Since Sensor A is being used in an optoelectronic sensor unit with a built in humidity probe, the relative humidity can be measured during the testing period. Thus, the relative humidity can be measured and be subtracted from the signal. Studies are also underway to develop a dual optical sensing approach to address the impact of moisture, and the results will be reported in the future.

General alcohol sensors such as commercial breathalyzers may also be susceptible to outside interferences such as food and other chemicals in the environment, leading to readings higher than normal and false positives [50]. The US National Highway Traffic Safety Administration (NHTSA) establishes guidelines and screenings 
for commercial breathalyzers in order to be approved as an alcohol sensing device [51]. These guidelines do not require a certain limit of detection to be met but require devices to conform to a set of tests to evaluate the precision and accuracy of the alcohol sensing device [51].

One of the major flaws of IR breathalyzers is the lack of specificity, since it is often the methyl group in ethanol that is being detected [49]. Thus the sensor will treat any compound with a methyl group as ethanol which includes many chemical compounds whose molecular structures are compatible with IR filters. Two IR wavelengths and an algorithm for the detection of interferents have been used in new breathanalyzers to calculate the ratio of absorbance values at the two measured wavelengths [50]. Also, the instrumentation for IR breathanalyzers can be complex with some requiring five filters to address volatile interferences [52]. Although such an approach reduces interference, acetone, e.g., was found to still have an effect on the new, IR-based breathanalyzers [53]. Semiconductor breathalyzers have been shown to absorb many substances which can give positive alcohol readings even when no ethanol is present [49]. Studies have confirmed the existence of a wide variety of compounds on the human breath [54]. Acetone and hexanes are among chemicals that are commonly found on the breath of normal, healthy individuals but are of insignificant levels to affect breathalyzers. However, dieters and diabetics not in control of their blood sugar can have acetone levels hundreds or even thousands of times higher than normal which may create falsely high results in a semiconductor breathalyzer [49]. Breathalyzers based on fuel cell technology give concerns due to sensitivity loss and sensor degradation after long term exposure in dry conditions [55]. The primary reason for sensitivity loss and sensor degradation is from the loss of electrochemically active surface area of the platinum electrode, which is seemingly irreversible [55]. Another concern for fuel cell sensors, albeit to a lesser extent, is the loss of proton conductivity as a result of membrane dehydration but can be alleviated by rehydrating the membrane in humid conditions [55]. There has been a report of a false-positive breath-alcohol test using a fuel-cell based analyzer after a ketogenic diet [56].

In comparison to commercial breathalyzers, Sensor $\mathbf{A}$ appears to be less prone to common interferences of current commercial alcohol sensors. Sensor A was directly exposed to interferents that are known for commercial breathalyzers such as acetone, hexanes, and food but gave a minute response to these interferences (Figure S7). The small responses are perhaps a result of solvent effects, as acetone [57] and hexanes do not react with the CIX dye. It is unclear why food interferes with common breathalyzers since it can cause one of the highest false positives in commercial breathalyzers [58]. However, it does not affect the response of Sensor A. The interference study here demonstrates that interferences without active $\mathrm{N}-\mathrm{H}$ or $\mathrm{O}-\mathrm{H}$ groups are unlikely to interfere with the response of Sensor A. The current study looks into a new method centered on a fluorescence based system for the detection of alcohol and provides an improvement over existing alcohol sensors by limiting the possible interferences that may affect a reading such as chemicals or dry conditions.

\section{Conclusion}

In this study, the CIX dye was incorporated into EC films in order to detect alcohol vapors. The ethyl cellulose sensor for alcohol vapors was sensitive to $\mathrm{MeOH}, \mathrm{EtOH}$, and $\mathrm{Pr}^{\mathrm{i}} \mathrm{OH}$. To induce Mie scattering, $\mathrm{TiO}_{2}$ particles were added to the alcohol sensors to increase the interaction of light with the indicator material which enhanced the sensitivity of the sensors. The use of $\mathrm{TiO}_{2}$ particles increased the signal of the emission intensity by approximately $30 \%$. The alcohol gas sensor reported in this study has a much higher dynamic range and lower limit of detection for the alcohols studied than the other gas alcohol sensors reported earlier. Among the interferences tested that are known to interfere with common alcohol sensors such as acetone, hexanes, and food vapors, they were shown not to interfere with the sensor in this study. Sensor A was tested with a miniaturized multi-channel testing platform, showing that they could be used under real world field testing conditions. The work found in this study may lead to the possibility of an optical sensor useful for a variety of different applications.

\section{Acknowledgements}

This work was supported by the NASA STTR program (07-1 T9.01-9883) and the US National Science Foundation (CHE-1012173 to ZLX).

\section{References}

[1] Costantini, M.G. (1993) Health Effects of Oxygenated Fuels. Environmental Health Perspectives, 101, 151-160. http://dx.doi.org/10.1289/ehp.93101s6151 
[2] Flipsen, B. (2010) Designing Microfuel Cells for Portable Electronics. Journal of Fuel Cell Science and Technology, 7, Article ID: 061014. http://dx.doi.org/10.1115/1.4001352

[3] http://www.epa.gov/ttn/atw/187polls.html

[4] Young, J.A. (2006) Methanol. Journal of Chemical Education, 83, 1131. http://dx.doi.org/10.1021/ed083p1131

[5] http://www.osha.gov/dts/chemicalsampling/data/CH 251600.html

[6] Finkelstein, Y. and Vardi, J. (2002) Progressive Parkinsonism in a Young Experimental Physicist Following LongTerm Exposure to Methanol. NeuroToxicology, 23, 521-525. http://dx.doi.org/10.1016/S0161-813X(02)00033-5

[7] Federal Register (2010) Environmental Protection Agency, 68094-68150.

[8] Torsner, E. (2010) Solving Corrosion Problems in Biofuels Industry. Corrosion Engineering Science and Technology, 45, 42-48. http://dx.doi.org/10.1179/147842209X12579401586726

[9] Oliverio, N., Jiang, L., Yilmaz, H. and Stefanopoulou, A. (2009) Ethanol Detection in Flex-Fuel Direct Injection Engines Using In-Cylinder Pressure Measurements. SAE International Journal of Fuels and Lubricants, 2, $229-241$.

[10] Zhang, Y., Zhi, Z. and Yang, F. (2010) Highly Sensitive and Selective Alcohol Sensor Based on Ag-Doped $\mathrm{In}_{2} \mathrm{O}_{3}$ Coating. Industrial \& Engineering Chemistry Research, 49, 3539-3543. http://dx.doi.org/10.1021/ie100197b

[11] Bangalore, A.S., Small, G.W., Combs, R.J., Knapp, R.B. and Kroutil, R.T. (1994) Automated Detection of Methanol Vapor by Open Path Fourier Transform Infrared Spectrometry. Analytica Chimica Acta, 297, 387-403. http://dx.doi.org/10.1016/0003-2670(94)00241-X

[12] Criddle, W.J., Parry, K.W. and Jones, T.P. (1987) On-Line Determination of Ethanol during Fermentation Process Using a Fuel Cell Sensor. Analyst, 112, 615-618. http://dx.doi.org/10.1039/an9871200615

[13] Win, D.T. (2006) Breath Alcohol Testers-Prevents Road Accidents. AU Journal of Technology, 10, 75-80. http://www.journal.au.edu/au_techno/2006/oct06/journalTechV10N2_aticle01.pdf

[14] Monblanc, P. and Lacan, B. (2005) US Patent No. 6942835 B2.

[15] Gonzalez, M.H., Araujo, G.C.L., Pelizaro, C.B., Menezes, E.A., Lemos, S.G., Batista de Sousaa, G. and Nogueira, A.R.A. (2008) Coconut Coir as Biosorbent for Cr(VI) Removal from Laboratory Wastewater. Journal of Hazardous Material, 159, 252-256. http://dx.doi.org/10.1016/j.jhazmat.2008.02.014

[16] Morey, T.E., Booth, M.M., Prather, R.A., Nixon, S.J., Boissoneault, J., Melker, R.J., Goldberger, B.A., Wohltjen, H. and Dennis, D.M. (2011) Measurement of Ethanol in Gaseous Breath Using a Miniature Gas Chromatograph. Journal of Analytical Toxicology, 35, 134-142. http://dx.doi.org/10.1093/anatox/35.3.134

[17] Gessei, T., Sato, H., Kazawa, E., Kudo, H., Saito, H. and Mitsubayashi, K. (2009) Bio-Sniffers for Ethanol and Acetaldehyde Using Carbon and Ag/AgCl Coated Electrodes. Microchimica Acta, 165, 179-186. http://dx.doi.org/10.1007/s00604-008-0117-z

[18] NASA Stennis Space Center (2007) Environmental Assessment for the Construction and Operation of the Constellation Program A-3 Test Stand. http://www.ssc.nasa.gov/environmental/docforms/eas/eas.html

[19] Tejwani, G.D., McVay, G.P., Langford, L.A. and St. Cyr, W.W. (2006) Planning for Plume Diagnostics for Ground Testing J-2X Engines at the SSC. Stennis Space Center, NASA.

http://ntrs.nasa.gov/archive/nasa/casi.ntrs.nasa.gov/20100003145_2010002997.pdf

[20] http://www.osha.gov/dts/chemicalsampling/data/CH_248400.html

[21] Dhillon, S. and von Burg, R. (1995) Isopropyl Alcohol. Journal of Applied Toxicology, 15, 501-506. http://dx.doi.org/10.1002/jat.2550150612

[22] Jones, A.W. (1992) Driving under the Influence of Isopropyl. Clinical Toxicology, 30, 153-155. http://dx.doi.org/10.3109/15563659208994457

[23] Stevens, N. and Akins, D.L. (2007) Dye-Doped Inorganic/Organic Composite Films as Fluorescence Sensors for Methanol Vapor. Sensors and Actuators B, 123, 59-64. http://dx.doi.org/10.1016/j.snb.2006.07.021

[24] Pang, F., Han, X., Chu, F., Geng, J., Cai, H., Qu, R. and Fang, Z. (2007) Sensitivity to Alcohols of a Planar Waveguide Ring Resonator Fabricated by a Sol-Gel Method. Sensors and Actuators B, 120, 610-614. http://dx.doi.org/10.1016/j.snb.2006.03.031

[25] McCorkle, D.L., Warmack, R.J., Patel, S.V., Mlsna, T., Hunter, S.R. and Ferrell, T.L. (2005) Ethanol Vapor Detection in Aqueous Environments Using Micro-Capacitors and Dielectric Polymers. Sensors and Actuators B, 107, 892-903. http://dx.doi.org/10.1016/j.snb.2004.12.051

[26] Stich, M.I.J., Fischer, L.H. and Wolfbeis, O.S. (2010) Multiple Fluorescent Chemical Sensing and Imaging. Chemical Society Reviews, 39, 3102-3114. http://dx.doi.org/10.1039/b909635n

[27] Holthoff, E.L. and Bright, F.V. (2007) Molecularly Imprinted Xerogels as Platforms for Sensing. Accounts of Chemical Research, 40, 756-767. http://dx.doi.org/10.1021/ar700087t 
[28] Maffei, F., Betti, P., Genovese, D., Montalti, M., Prodi, L., Zorzi, R.D., Geremia, S. and Dalcanale, E. (2011) Highly Selective Chemical Vapor Sensing by Molecular Recognition: Specific Detection of C1-C4 Alcohols with a Fluorescent Phosphonate Cavitand. Angewandte Chemie International Edition, 50, 4654-4657.

[29] Tonezzer, M., Quaranta, A., Maggioni, G., Carturan, S. and Mea, G.D. (2007) Optical Sensing Responses of Tetraphenyl Porphyrins toward Alcohol Vapours: A Comparison between Vacuum Evaporated and Spin-Coated Thin Films. Sensors and Actuators B: Chemical, 122, 620-626. http://dx.doi.org/10.1016/j.snb.2006.07.009

[30] Zhang, Z.H., Lockwood, R., Veinot, J.G.C. and Meldrum, A. (2013) Detection of Ethanol and Water Vapor with Silicon Quantum Dots Coupled to an Optical Fiber. Sensors and Actuators B: Chemical, 181, 523-528. http://dx.doi.org/10.1016/j.snb.2013.01.070

[31] Mohr, G.J., Citterio, D. and Spichiger-Keller, U.E. (1998) Development of Chromogenic Reactands for Optical Sensing of Alcohols. Sensors and Actuators B, 49, 226-234. http://dx.doi.org/10.1016/S0925-4005(98)00132-4

[32] Mohr, G.J. and Spichiger-Keller, U.E. (1997) Novel Fluorescent Sensor Membranes for Alcohols Based on p- $N, N$-dioctylamino-4'-Trifluoroacetylstilbene. Analytica Chimica Acta, 351, 189-196. http://dx.doi.org/10.1016/S0003-2670(97)00365-6

[33] Mohr, G.J., Lehmann, F., Grummt, U. and Spichiger-Keller, U.E. (1997) Fluorescent Ligands for Optical Sensing of Alcohols: Synthesis and Characterisation of p- $N, N$-dialkylamino-Trifluoroacetylstilbenes. Analytica Chimica Acta, 344, 215-225. http://dx.doi.org/10.1016/S0003-2670(97)00113-X

[34] Wriedt, T. (1998) A Review of Elastic Light Scattering Theories. Particle \& Particle Systems Characterization, 15, 67-74. http://dx.doi.org/10.1002/(SICI)1521-4117(199804)15:2<67::AID-PPSC67>3.0.CO;2-F

[35] Carrington, N.A., Thomas, G.H., Rodman, D.L., Beach, D.B. and Xue, Z.L. (2007) Optical Determination of Cr(VI) Using Regenerable, Functionalized Sol-Gel Monoliths. Analytica Chimica Acta, 581, 232-240. http://dx.doi.org/10.1016/j.aca.2006.08.032

[36] Allain, L.R. and Xue, Z.L. (2000) Optical Sensors for the Determination of Concentrated Hydroxide. Analytical Chemistry, 72, 1078-1083. http://dx.doi.org/10.1021/ac990908b

[37] Canada, T.A. and Xue, Z.L. (2002) High-Basicity Determination in Mixed Water-Alcohol Solutions by a Dual Optical Sensor Approach. Analytical Chemistry, 74, 6073-6079. http://dx.doi.org/10.1021/ac0202987

[38] Fong, J.K. and Xue, Z.L. (2013) A Dye-Doped Optical Sensor for the Detection of Biodiesel in Diesel. Chemical Communications, 49, 9015-9017. http://dx.doi.org/10.1039/c3cc43958e

[39] Dansby-Sparks, R.N., Jin, J., Mechery, S.J., Sampathkumaran, U., Owen, T.W., Yu, B.D., Goswami, K., Hong, K., Grant, J. and Xue, Z.L. (2010) Fluorescent-Dye-Doped Sol-Gel Sensor for Highly Sensitive Carbon Dioxide Gas Detection below Atmospheric Concentrations. Analytical Chemistry, 82, 593-600. http://dx.doi.org/10.1021/ac901890r

[40] Dean, J.A. (1999) Lange’s Handbook of Chemistry. 15th Edition, McGraw-Hill, New York, 5.30.

[41] Nakata, K., Sakai, M., Ochiai, T., Murakami, T., Takagi, K. and Fujishima, A. (2012) Fabrication and Characterization of Self-Organized Porous $\mathrm{TiO}_{2}$ Particle Layers. Materials Letters, 70, 160-162. http://dx.doi.org/10.1016/j.matlet.2011.12.016

[42] You, J.H. and Hsu, K.Y. (2010) Preparation of Submicron-Sized Porous Titanium Oxide Particles by the Swelling Process. Chemical Engineering Research and Design, 88, 1049-1056. http://dx.doi.org/10.1016/j.cherd.2010.01.033

[43] DuPont's R706 Product Sheet. http://www2.dupont.com/Titanium_Technologies/en_US/products/706/CO_B_H_56619_7_706_Grade_Description.pdf

[44] AlcoMate AL-7000 Product Sheet. http://alcomate.net/prodmanuals/manual_Premium.pdf

[45] AlcoHawk Precision Product Sheet. http://www.q3i.com/pdfs/AlcoHAWK-Precision-Datasheet.pdf

[46] Bactrack S30 Product Sheet. http://www.bactrack.com/breathalyzer/images/s30-ownersmanual.pdf

[47] Schmidt, E.W. and Wucherer, E.J. (2004) Hydrazine(s) vs. Nontoxic Propellants—Where Do We Stand Now? In: Wilson, A., Ed., Proceedings of the 2nd International Conference on Green Propellants for Space Propulsion (ESA SP-557), Chia Laguna (Cagliari), Sardinia, 7-8 June 2004. http://adsabs.harvard.edu/full/2004ESASP.557E...3S

[48] Plemmons, D.H., Mehta, M., Clark, B.C., Kounaves, S.P., Peach Jr., L.L., Renno, N.O., Tamppari, L. and Young, S.M.M. (2008) Effects of the Phoenix Lander Descent Thruster Plume on the Martian Surface. Journal of Geophysical Research, 113, Article ID: E00A11. http://dx.doi.org/10.1029/2007JE003059

[49] Taylor, L. and Oberman, S. (2006) Drunk Driving Defense. 6th Edition, Aspen, New York.

[50] Mohr, G.J., Citterio, D., Demuth, C., Fehlmann, M., Jenny, L., Lohse, C., Moradian, A., Nezel, T., Rothmaier, M. and Spichiger, U.E. (1999) Reversible Chemical Reactions as the Basis for Optical Sensors Used to Detect Amines, Alcohols, and Humidity. Journal of Materials Chemistry, 9, 2259-2264. http://dx.doi.org/10.1039/a901961h

[51] Federal Register (2008) National Highway Traffic Safety Administration, 16956-16960.

[52] Jones, A.W. and Anderson, L. (2008) Determination of Ethanol in Breath for Legal Purposes Using a 5-Filter Infrared 
Analyzer: Studies on Response to Volatile Interfering Substances. Journal of Breath Research, 2, 7152-7155. http://dx.doi.org/10.1088/1752-7155/2/2/026006

[53] Watterson, J.H. (2009) Assessment of Response of the Intoxilzyer 8000C to Volatiles of Forensic Relevance in Vitro, Part I: Acetone, Isopropanol, and Methanol. Journal of Analytical Toxicology, 33, 109-117. http://dx.doi.org/10.1093/jat/33.2.109

[54] Conkle, J.P., Camp, B.J. and Welch, B.F. (1975) Trace Composition of Human Respiratory Gas. Archives of Environmental Health: An International Journal, 30, 290-295. http://dx.doi.org/10.1080/00039896.1975.10666702

[55] Prest, L. (2011) Fundamental Investigation of Fuel Cell-Based Breath Alcohol Sensors and the Cause of Sensor Degradation in Low-Humidity Conditions. M.S. Thesis, University of Ontario Institute of Technology, Oshawa.

[56] Jones, A.W. and Roessner, S. (2007) False-Positive Breath-Alcohol Test after a Ketogenic Diet. International Journal of Obesity, 31, 559-561. http://dx.doi.org/10.1038/sj.ijo.0803444

[57] Loudon, G.M. (1995) Organic Chemistry. 3rd Edition, Benjamin/Cummins Publishing Company, San Francisco, 654.

[58] Logan, B.K. and Distefano, S. (1998) Ethanol Content of Various Food and Soft Drinks and Their Potential for Interference with a Breath-Alcohol Test. Journal of Analytical Toxicology, 22, 181-183. http://dx.doi.org/10.1093/jat/22.3.181

\section{Appendix. Supplementary Data}

The following supplementary data associated with this article can be found in the online version: Spectra of Sensor D (Figure S1); Responses of Sensors D (Figure S2 and Figure S3), F (Figure S4), and A (Figure S5) to $\mathrm{Pr}^{\mathrm{i} O H}$ vapor; Baseline study of Sensor A over the 8-month period (Figure S6); Response of Sensor A to interferent vapors $\mathrm{CO}_{2}$, kerosene, ethylene glycol, and $\mathrm{NH}_{3}$ (Figure S7).

\section{Supporting Material}

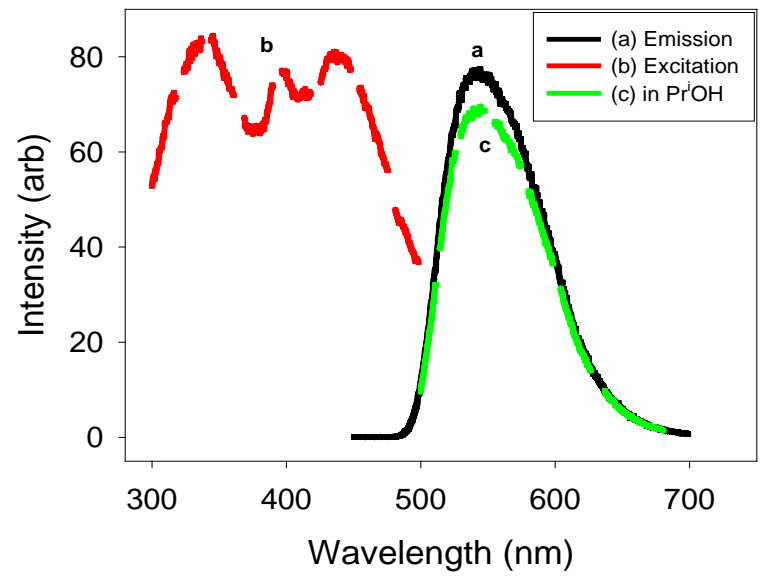

Figure S1. Excitation/Emission spectra of PVC Sensor D and signal quenching upon exposure to $1.092 \mathrm{~mol} \% \mathrm{Pr}^{\mathrm{i}} \mathrm{OH}$ vapor. 


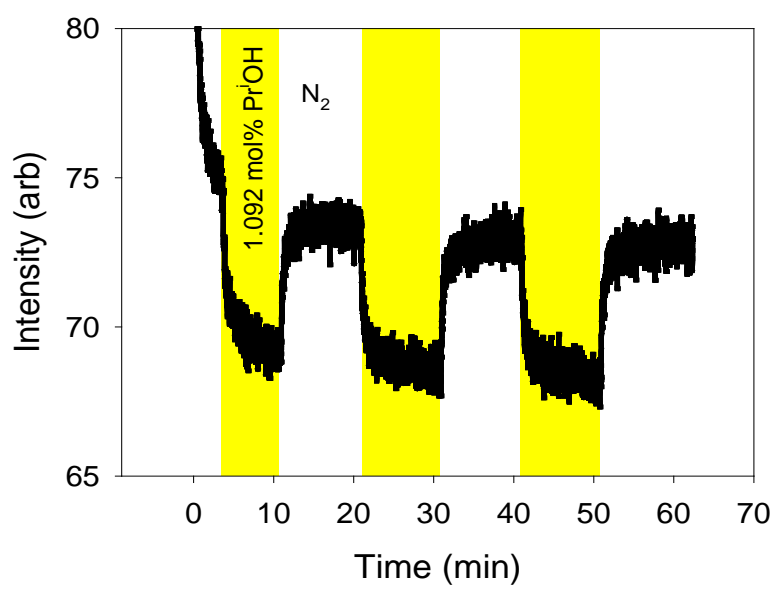

Figure S2. Time-based emission of Sensor D at $540 \mathrm{~nm}$ demonstrating a signal quenching response when exposed to $1.092 \mathrm{~mol} \% \mathrm{Pr}^{\mathrm{i} O H}$ in nitrogen gas without signal averaging or background correction.

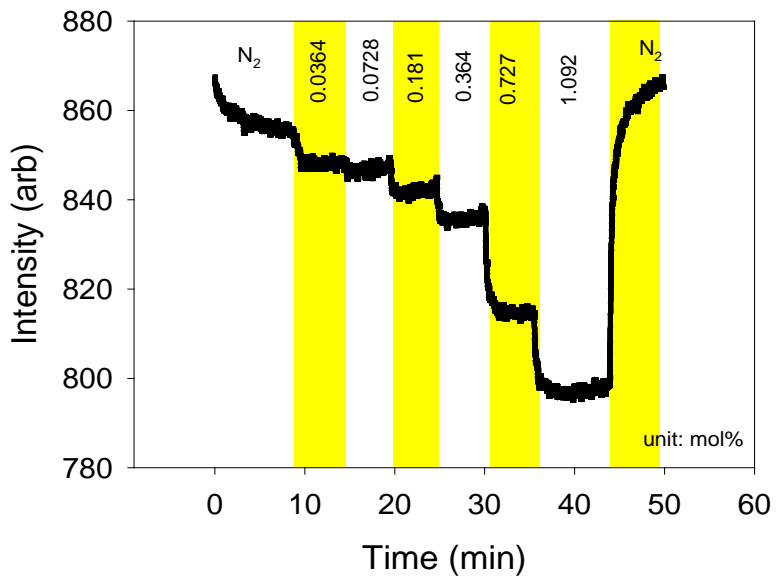

Figure S3. Response of Sensor D to 0.0364 - 1.092 mol\% $\mathrm{Pr}^{\mathrm{i} O H}$ with signal averaging and baseline correction.

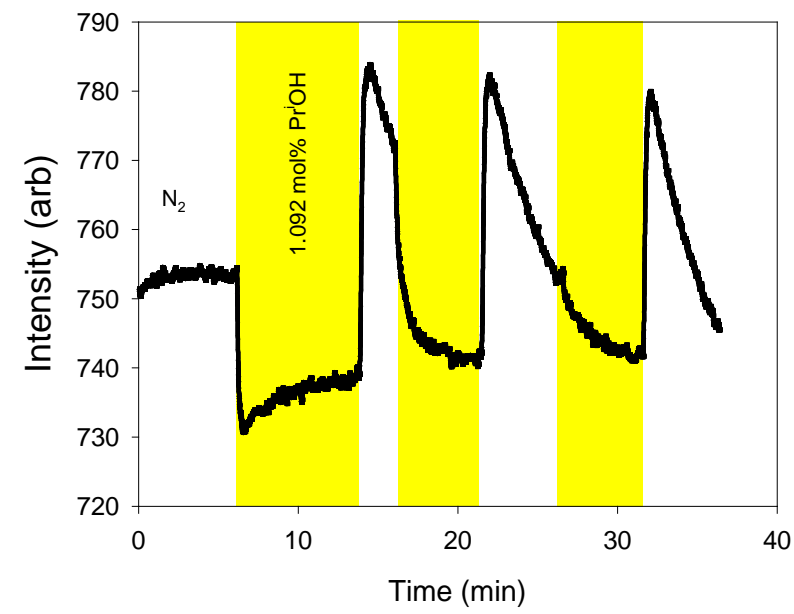

Figure S4. Response of the sol-gel Sensor $\mathbf{F}$ on exposure to $1.092 \mathrm{~mol} \%$ pulses of $\mathrm{Pr}^{\mathrm{i}} \mathrm{OH}$ vapor; Emission was detected at $580 \mathrm{~nm}$. 


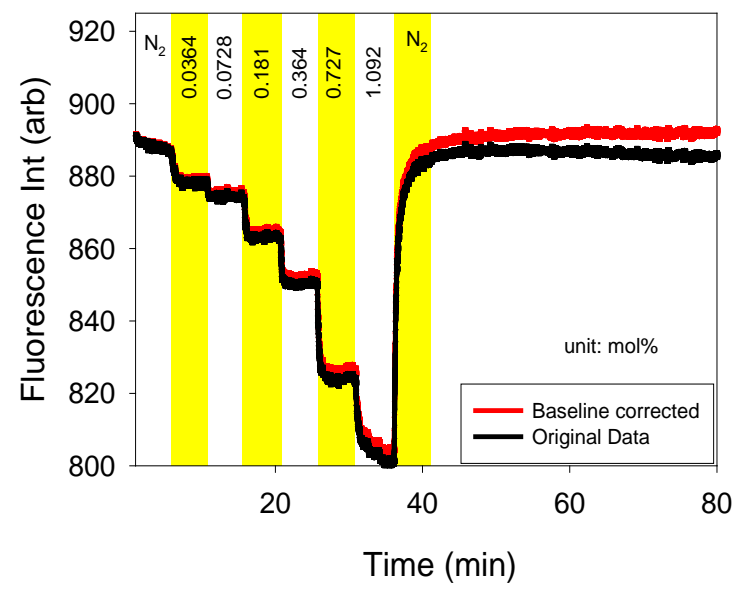

Figure S5. Response of Sensor A to PrïH vapors.

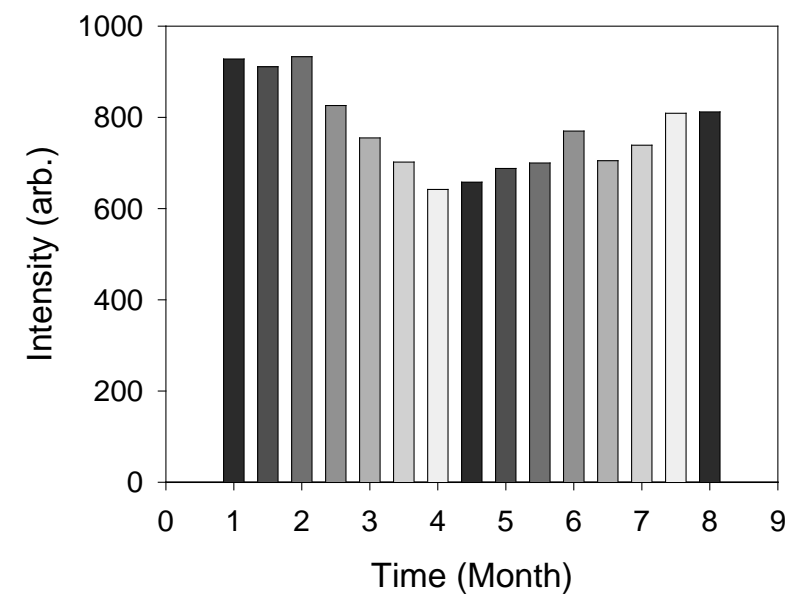

(a)

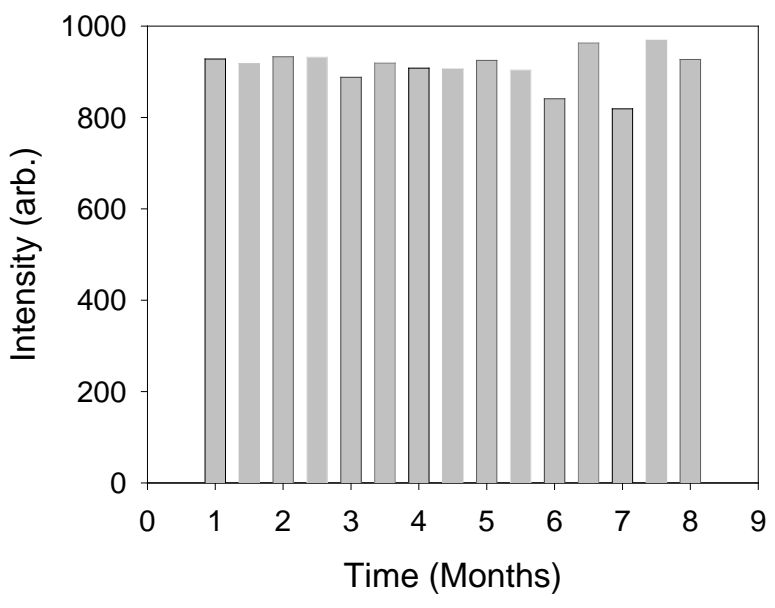

(b)

Figure S6. Baseline study of Sensor A: (a) One sensor over an 8-month period; (b) Freshly opened sensors over an 8-month period.

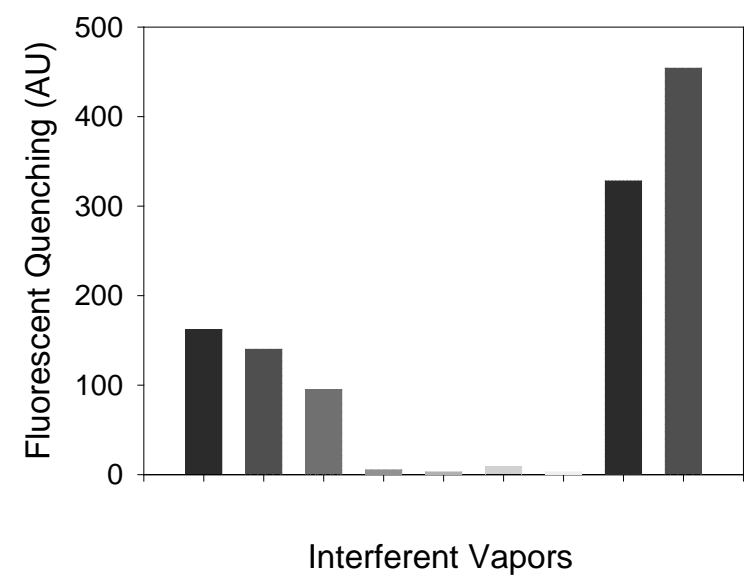

Figure S7. Response of the alcohol sensor to interferent vapor $\mathrm{CO}_{2}$, kerosene, ethylene glycol, and $\mathrm{NH}_{3}$. 
Scientific Research Publishing (SCIRP) is one of the largest Open Access journal publishers. It is currently publishing more than 200 open access, online, peer-reviewed journals covering a wide range of academic disciplines. SCIRP serves the worldwide academic communities and contributes to the progress and application of science with its publication.

Other selected journals from SCIRP are listed as below. Submit your manuscript to us via either submit@scirp.org or Online Submission Portal.
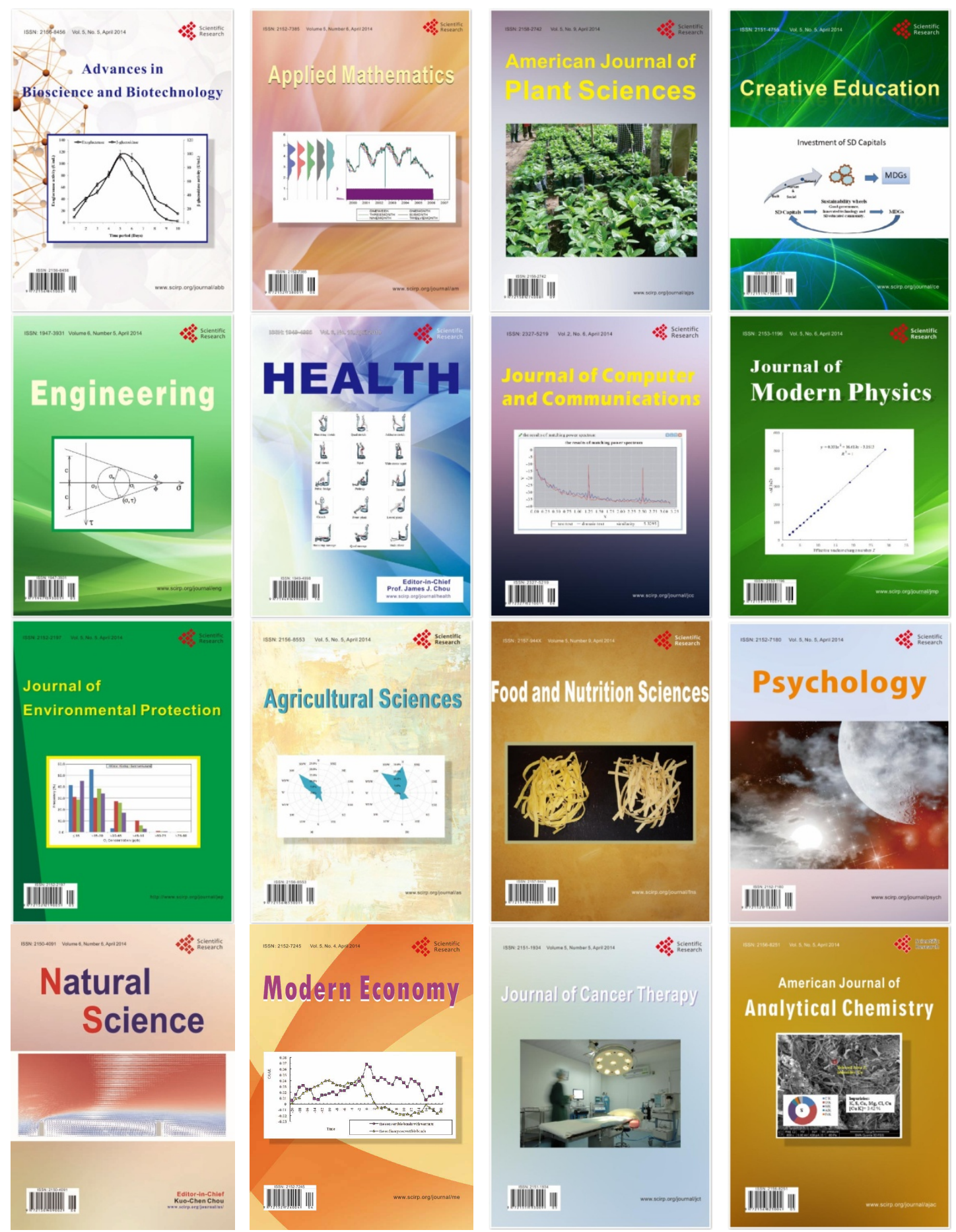